\title{
Revista Brasileira de Enfermagem REBEn \\ Cooperação versus colaboração: conceitos para o ensino de enfermagem em ambiente virtual
}

REVISÃO

\author{
Cooperation versus collaboration: concepts for nursing teaching in virtual environment \\ Cooperación versus colaboración: conceptos para la enseñanza de enfermería en \\ ambiente virtual
}

Ana Luísa Petersen Cogo

Enfermeira. Mestre em Educação. Professora Assistente da Escola de Enfermagem da Universidade Federal do Rio Grande do Sul, Porto Alegre, RS.

\section{RESUMO}

Este artigo de revisão objetiva apresentar os conceitos de cooperação e colaboração na perspectiva da teoria de Jean Piaget. Sua importância reside no fato da crescente utilização de ambientes virtuais de aprendizagem no ensino de enfermagem, os quais possibilitam o trabalho em grupo e o desenvolvimento de projetos em uma proposta construtivista-interacionista. As relações de trocas sociais ocorrem entre os sujeitos da aprendizagem: a cooperação dá-se quando há construção do conhecimento; e a colaboração; quando existem trocas de pensamentos, como numa comunicação verbal. A compreensão desses conceitos possibilita entender-se qual a dimensão desenvolvida nas atividades pedagógicas de enfermagem propostas em ambiente virtual.

Descritores: Educação em enfermagem; Aprendizagem, Internet.

\section{ABSTRACT}

This paper presents the concepts of cooperation and collaboration in the light of Jean Piaget's theory. The importance of his theory resides in the increasing use of virtual learning environments for nursing teaching; these virtual environments enable group work and the development of projects under a constructivist-interactionist perspective. Social exchange relations take place between learning subjects; there is cooperation when there is construction of knowledge and collaboration when there are exchanges of thoughts, just as it happens in verbal communication. Understanding these concepts enables one to understand the dimension developed in pedagogical activities in nursing education proposed in a virtual environment.

Descriptors: Education, nursing; Learning; Internet.

\section{RESUMEN}

Este artículo de revisión objetiva presentar los conceptos de cooperación y colaboración bajo la perspectiva de la teoría de Jean Piaget. Su importancia reside en el hecho de la creciente utilización de ambientes virtuales de aprendizaje en el enseño de enfermería, los cuales posibilitan el trabajo en grupo y el desarrollo de proyectos desde una propuesta constructivista-interaccionista. Las relaciones de intercambios sociales ocurren entre los sujetos del aprendizaje: la cooperación se da cuando hay construcción del conocimiento; ya la colaboración, cuando hay intercambios de pensamientos, como en una comunicación verbal. La comprensión de esos conceptos posibilita entenderse cuál es la dimensión desarrollada en las actividades pedagógicas de enfermería propuestas en ambiente virtual.

Descriptores: Educación en enfermería; Aprendizaje; Internet.

Cogo ALP. Cooperação versus colaboração: conceitos para o ensino de enfermagem em ambiente virtual. Rev Bras Enferm 2006 set-out; 59(5): 680-3.

\section{INTRODUÇÃO}

A educação na modalidade à distância vem sendo difundida nos últimos anos na enfermagem, demonstrando as amplas possibilidades que estes recursos oferecem no ensino do cuidado. No atual estado do conhecimento, percebe-se que a enfermagem tem relatado suas experiências no desenvolvimento de tecnologias computacionais no ensino, seja no desenvolvimento de software ou de atividades via Internet. Desta forma, com as experiências na utilização de ambientes virtuais de aprendizagem, acredita-se que neste momento devam ser aprofundados conceitos, como o de cooperação e o de colaboração, que subsidiem essas práticas de ensino, em especial na enfermagem.

As tecnologias da informação e da comunicação, quando empregadas em atividades de ensino, possuem uma lógica de funcionamento diferenciada das atividades presenciais. Enquanto a modalidade presenciai
Submissão: 05/07/2005

Aprovação: 02/03/2006 
privilegia a oralidade e as expressões gestuais entre o educador e os alunos nas atividades em tempo síncrono, a modalidade à distância resgata a comunicação escrita e abre a possibilidade das atividades de aprendizagem ocorrerem em tempo assíncrono(1).

Em relação à modalidade à distância, outra característica que vem sendo explorada é o trabalho em grupo. Esta técnica permite romper com a monotonia do trabalho individual, servindo como estímulo mútuo entre os participantes, $e$ assim promove trocas de aprendizagem, rompendo com a hierarquia professoraluno, pois o professor torna-se um facilitador do processo. A concepção de ensino apresentada é colocada por autores ${ }^{(2)}$ como uma utilização inteligente do computador na educação, na qual o aluno usaria as ferramentas no intuito de construir conhecimento, criando, pensando e manuseando diferentes tipos de informação.

Essas peculiaridades das atividades de aprendizagem mediadas por computador requerem dos educadores a habilidade de empregarem conceitos como o de cooperação e o de colaboração. No entanto, observam-se dúvidas entre educadores ao buscarem um conceito que expresse a dimensão atingida nos processos de aprendizagem mediados por computador por eles desenvolvidos. Afinal, os alunos teriam interagido trocando informações entre si ou aprofundado esta interação realizando trocas significativas para o seu aprendizado?

Acredita-se que o desdobramento dos conceitos de cooperação e de colaboração merece uma investigação mais minuciosa e elaborada. Existem, com freqüência, divergências conceituais no meio acadêmico entre cooperar e colaborar. No entender de alguns autores, entre estes pode-se citar Campos ${ }^{(3)}$, a cooperação é um nível intermediário de compartilhamento das atividades em comunidades virtuais, com discussão temática e estabelecimento de normas de trabalho coletivo no intuito de realizar uma tarefa. A colaboração compreenderia a construção de conhecimentos com objetivos estabelecidos e compartilhados com os participantes desta comunidade virtual, sendo superior o nível de relação social. No entanto, cooperação e colaboração são apresentadas por Piaget de forma inversa, sendo a cooperação o grau mais elevado de socialização.

Este artigo pretende contribuir, apresentando uma revisão conceitual sobre cooperação e colaboração; para tanto, optou-se como referencial teórico pela teoria da epistemologia genética de Jean Piaget, por entender que a proposta construtivista-interacionista é relevante na proposição de práticas pedagógicas em enfermagem mediadas por computador. O texto apresentado é decorrente do trabalho apresentado na disciplina 'As coordenações das ações sociais na obra de Jean Piaget' do Programa de Pós-Graduação em Educação da Universidade Federal do Rio Grande do Sul, ministrada pela Prof. ${ }^{a}$ Dr. ${ }^{a}$ Maria Luiza Becker.

\section{CONTEXTUALIZAÇÃO DOS CONCEITOS}

\subsection{Epistemologia Genética}

A epistemologia genética pode ser compreendida como uma teoria processual, a qual concebe a construção do conhecimento na ação do sujeito. $O$ conhecimento, no entendimento de Jean Piaget ${ }^{(4)}$, não está pré-determinado nas estruturas internas do sujeito, nem nas características do objeto, mas sim na interação que ocorre entre o sujeito e o objeto. Portanto, o desenvolvimento do sujeito epistêmico possui uma dimensão social, e não apenas individual, na construção do conhecimento e do pensamento ${ }^{(5)}$.

A concepção de que não existe um conhecimento absoluto, que cada sujeito faz o seu percurso cognitivo passando de um patamar mais básico para um mais elaborado de conhecimento, e especialmente que não se faz este percurso sozinho, mas na interação com outros sujeitos, são algumas das questões presentes nesta teoria concebida como sendo construtivistainteracionista ${ }^{(4)}$.

O momento histórico vivenciado por Jean Piaget, de reflexão pedagógica na busca de mudanças frente à denominada pedagogia tradicional, fez com que este biólogo aproximasse os seus estudos de temas de interesse para a educação, demonstrando uma preocupação política e intelectual pelas ações educativas na virada do século XIX para o XX(6).

O movimento da Escola Nova, tendo como um dos seus difusores Pierre Bovet, surgiu nesta fase de mudanças propondo métodos novos, os quais privilegiavam a construção da autonomia e a aprendizagem pela atividade, partindo dos interesses dos alunos. O enfoque central passa a ser no aluno, $e$ não no professor como nas práticas tradicionais ${ }^{(7)}$.

Frente ao momento sócio-histórico, Piaget contribuiu com as fundamentações psicológica e epistemológica necessárias para dar sustentação às propostas da pedagogia ativa. Em 1932, às vésperas da $2^{2}$ Guerra Mundial, apresentava em um congresso as contribuições da Educação Nova para o progresso social, desenvolvendo a sua argumentação a partir do conceito de egocentrismo, apontando a relação entre liberdade e constrangimento na sociedade, reforçando que a sociedade deveria preocupar-se com a cooperação e com a reciprocidade ${ }^{(7)}$.

Como foi demonstrado, a proposta da Educação Nova surgiu como um movimento, em diferentes países, de repensar as práticas pedagógicas em um momento histórico marcado por políticas autoritárias e de intolerâncias raciais. 0 argumento central desta proposição, e que pode-se transpor ao início do século XXI, é a força existente na educação como uma prática transformadora. Para tanto, deve-se resgatar o fazer docente, revendo os métodos tradicionais.

Os métodos propostos pela pedagogia ativa compreendem procedimentos como o trabalho em grupo e o self-government, que visam favorecer a formação do pensamento, a pesquisa e a promoção da autonomia. Nesta perspectiva, as relações professor-aluno e aluno-aluno serão construídas fundamentadas no respeito mútuo, na reciprocidade e na cooperação. Os alunos, nas atividades do trabalho em grupo, realizam trocas entre si, colaborando mutuamente, mas a construção de uma lógica do pensamento ocorrerá quando a cooperação estiver estabelecida ${ }^{(8)}$.

Como está sinalizado, colaborar e cooperar possuem perspectivas qualitativas diferenciadas no entendimento de Piaget. Essas dimensões serão analisadas a seguir, destacando-se os aspectos psicológicos que as constituem.

\subsection{Cooperação e Colaboração}

O homem é essencialmente um ser social, que não pode ser pensado fora desta perspectiva, ocorrendo através das interações sociais o desenvolvimento da inteligência humana. A socialização do sujeito não é expressa da mesma forma nas diferentes faixas etárias, utilizando como critério a qualidade das trocas intelectuais. O social nas relações de uma criança é qualitativamente diferente do social presente nas relações de um adolescente ${ }^{(9)}$.

Para que haja uma compreensão dos conceitos de cooperação e colaboração, faz-se necessário destacar alguns aspectos do desenvolvimento psicológico dos indivíduos. Piaget ${ }^{(3)}$ identificou quatro estágios do desenvolvimento que seriam a fase sensório-motora, que precede a linguagem; a pré-operatória, que corresponde ao período das representações iniciando com a linguagem; a das operações concretas e a operatória formal. Essas etapas seriam sucessivas no desenvolvimento do indivíduo, variando apenas cronologicamente.

A socialização da inteligência inicia-se com a aquisição da linguagem; antes, na fase sensório-motora, a criança basicamente não realiza trocas sociais, permanecendo em uma perspectiva individual ${ }^{(9)}$.

$\mathrm{Na}$ fase pré-operatória irá sobrepujar-se o egocentrismo cognitivo, definido como "....) uma atitude epistêmica que impressiona por sua apreensão nãocrítica do objeto de conhecimento e sua tendência à indiferenciação, em razão da supremacia da perspectiva própria"(10). Portanto, o termo egocentrismo refere-se à impossibilidade do sujeito descentrar-se para poder compreender a perspectiva de outros sujeitos ${ }^{(11)}$.

A descentração corresponde à capacidade do indivíduo refazer o percurso cognitivo de outro sujeito, buscando compreender o pensamento do outro afastando-se da sua lógica individual. Deve-se destacar que todo indivíduo adolescente ou adulto preservará, em menor ou maior grau, traços de 
egocentrismo, necessitando descentrar-se para cooperar. O pensamento egocêntrico constitui-se em uma fase pré-social, antecipando a cooperação presente nos aspectos sociais do conhecimento(10).

Nesta perspectiva, não há uma separação entre social e não social, mas graus de socialização entre sujeitos em nível operatório, ou seja, com a possibilidade de socialização do pensamento e de trocas intelectuais, elementos imprescindíveis para que os indivíduos possam descentrar-se e, conseqüentemente, cooperarem ${ }^{(9)}$.

O termo operatório refere-se a operações mentais, compreendidas como "elementos constitutivos do pensamento lógico"(10), caracterizando-se por ser uma ação interiorizada, reversível e constitutiva de uma estrutura.

No entendimento de Piaget, cooperação é um método construído na reciprocidade entre os indivíduos, que ocorre pela descentração intelectual, havendo a construção não apenas de normas morais, mas também racionais, tendo a razão como produto coletivo ${ }^{(10,12)}$.

A colaboração seria uma interação em que existem trocas de pensamento, seja por comunicação verbal ou coordenações de pontos de vista, de discussão, sem ocorrer operações racionais, não havendo uma estrutura operatória ${ }^{(13)}$. Comparativamente poder-se-ia afirmar que a colaboração representa uma etapa das trocas sociais anterior à cooperação.

A cooperação está vinculada à interação, a qual requer a formação de vínculos e a reciprocidade afetiva entre os sujeitos do processo de aprendizagem. As interações interindividuais possibilitam a modificação do sujeito na sua estrutura cognitiva e do grupo como um todo, não em caráter somatório, mas em uma perspectiva de formação de um sistema de interações. Neste entendimento, a construção do conhecimento ocorrerá através da cooperação ${ }^{(13)}$.

A interação sócio-cognitiva demonstra que os sujeitos, ao cooperarem, solucionam problemas cognitivos de forma qualitativamente diferente do que teriam realizado individualmente ${ }^{(14)}$. No entanto, para que a cooperação ocorra há a necessidade de existir respeito mútuo e reciprocidade entre os sujeitos que estão interagindo, que são os componentes de uma moral autônoma ${ }^{(15)}$.

Cabe diferenciar a moral heterônoma da moral autônoma. A moral heterônoma refere-se as relações nas quais prevalecem a imposição, a coação e a coerção exercida por um indivíduo sobre os demais. A submissão é a resposta do grupo as ações exercidas, não havendo uma troca de valores justa, o respeito ocorre de forma unilateral. Portanto, não ocorrerá a construção de um espaço social de autonomia e responsabilidade. Na moral autônoma, os sujeitos participam da composição das regras de respeito mútuo, portanto percebem os seus limites de forma mais justa e construtiva ${ }^{(15)}$.

Como foi demonstrado, a cooperação, diferentemente da colaboração, é um processo criador de realidades novas, e não somente de trocas entre os indivíduos ${ }^{(10)}$.

\section{APLICAÇÃO NA EDUCAÇÃO À DISTÂNCIA EM ENFERMAGEM}

Entende-se cooperação como um dos conceitos fundamentais da Teoria de Jean Piaget, que subsidia a proposta de aprendizagem construtivista-

\section{interacionista.}

Na busca de uma coerência com a proposta de Piaget, a cooperação em processos de aprendizagem em ambientes virtuais pode ser desenvolvida em atividades síncronas (chat) ou assíncronas (fórum, correio eletrônico), com a possibilidade de utilização das tecnologias computacionais em consonância com uma proposta pedagógica que desenvolva a autonomia ea construção do conhecimento.

Frente a esta perspectiva, cabe destacar que o uso das tecnologias computacionais não garante por si só a aprendizagem, cabendo ao professor a proposição de projetos que integrem os recursos disponíveis em uma abordagem pedagógica construtivista ${ }^{(16)}$. Afigura do professoré descentralizada, esta fica intermediada pelo computador, fato este que auxilia a desconstruir o papel heterônomo do docente, promovendo a interação entre os sujeitos envolvidos.

A perspectiva ativa do aluno no processo de aprendizagem em ambiente virtual na enfermagem implica em aprender a aprender coletivamente, proporcionando ao mesmo o desenvolvimento de projetos que o desafie, que instigue a sua capacidade criativa e de resolução de problemas ${ }^{(17)}$. Da mesma forma, o professor torna-se um facilitador do processo, deixando de ser um informador ${ }^{(18)}$

A enfermagem, que durante a sua construção sócio-histórica esteve muito voltada às práticas pedagógicas presenciais centradas na atividade, beneficiase da perspectiva construtivista aplicada em ambiente virtual. O processo de aprendizagem cooperativo antecipa aos alunos a experiência de convívio mútuo e de relacionamentos interpessoais que terão em práticas de estágio e no contato com o cliente e sua família.

Da mesma forma, o desenvolvimento de projetos em grupos possibilita ao aluno a construção de regras de convívio mútuo, que são quesitos importantes para a inserção profissional do futuro enfermeiro, uma vez que o trabalho da enfermagem desenvolve-se coletivamente.

\section{CONSIDERAÇÕES FINAIS}

O desenvolvimento de atividades em ambientes virtuais de aprendizagem, neste caso na área da enfermagem, requer a contextualização teórica dos conceitos que estão sendo empregados. Como procurou-se demonstrar os autores muitas vezes utilizam indiscriminadamente as palavras cooperação e colaboração, o que deve ser desvelado para compreender-se a dimensão que a atividade educativa atingiu. Na perspectiva de Piaget, a construção do conhecimento somente ocorrerá se os alunos cooperarem. A colaboração refere-se à troca de informações entre os sujeitos envolvidos no processo de aprendizagem, com a conotação de ato solidário.

Como já foi mencionado, o que faz a diferença no uso dos recursos tecnológicos na área da educação não são os equipamentos, mas o que os educadores podem propor através destes. Existe hoje uma grande variedade de recursos computacionais, mas somente com a sua otimização e a aplicação de uma prática pedagógica cooperativa e crítica é que consegue-se avançar em relação às práticas ditas tradicionais.

\section{REFERÊNCIAS}

1. Dias DC, Cassiani SHB. Educação sem distâncias: utilização do WebCT como ferramenta de apoio para o ensino da Terapia Intravenosa na Graduação em Enfermagem. Rev Bras Enferm 2003; 56(4): 443-6.

2. Valente JA. $O$ uso inteligente do computador na educação. PátioRev Pedagógica 1997; 1(1): 19-21.

3. Campos M. Comunidades em rede: da publicação à construção de conhecimentos. In: Maraschin C, Freitas LBL, Carvalho DC. Psicologia \& Educação. Porto Alegre (RS): Editora da UFRGS 2003.

4. Piaget J. A epistemologia genética. $2^{\mathrm{a}}$ ed. Petrópolis (RJ): Vozes; 1973.
5. Rijsman J. O panorama intelectual e tecnológico da cena piagetiana. In: Barrelet JM, Perret-Clermont NA, organizadores. Jean Piaget- aprendiz e mestre. Lisboa (POR): Instituto Piaget; 1990. p. 191-218.

6. Zittoun T, Barrelet JM, Perret-Clermont AN. Um sábio no seu século. In: Barrelet JM, Perret-Clermont NA, organizadores. Jean Piaget- aprendiz e mestre. Lisboa (POR): Instituto Piaget; 1990. p. 173-90.

7. Oelkers J. A educação nova. In: Barrelet JM, Perret-Clermont NA, organizadores. Jean Piaget- aprendiz e mestre. Lisboa (POR): Instituto Piaget; 1990. p. 219-34. 
8. Parrat-Dayan S, Tryphon A. Introdução. In: Piaget J. Sobre a pedagogia. São Paulo (SP): Casa do Psicólogo; 1998.

9. La Talle Y. O lugar da interação social na concepção de Jean Piaget. In: La Talle Y, Oliveira MK, Dantas H. Piaget, Vygotsky, Wallon- teorias psicogenéticas em discussão. $5^{\text {a }}$ ed. São Paulo (SP): Summus; 1992.

10. Montangero J, Maurice-Naville D. Piaget ou a inteligência em evolução. Porto Alegre (RS): Artmed; 1998.

11. Castorina JA, Faigenbaum G, Clemente F, Lombardo E. Conhecimento individual e sociedade em Piaget: implicações para a investigação psicológica. Educação e Realidade 2002; 27(1): 28-33.

12. Piaget J. Sobre a pedagogia. São Paulo (SP): Casa do Psicólogo; 1998.

13. Piaget J. Estudos sociológicos. São Paulo (SP): Companhia Editora Forense; 1973.
14. Perret-Clermont AN. A interação social como espaço de pensamento (palestra). Porto Alegre (RS): Faculdade de Educação, Universidade Federal do Rio Grande do Sul; 1992.

15. Piaget J. 0 juízo moral na criança. São Paulo (SP): Summus; 1994.

16. Gil JMS. A caixa de surpresas: possibilidades educativas da informática. Pátio-Revista Pedagógica 1999; 3(9): 11-5.

17. Cogo ALP, Pedro ENR, Severo CL. Construindo o aprender enfermagem: exame físico e anamnese a partir de imagens. In: Creutzberg M, Funck LB, Kruse MHL, Mancia J, organizadores. Livro-Temas do $56^{\circ}$ Congresso Brasileiro de Enfermagem (online); 2004 out 24-29 (citado em: 23 mai 2005); Gramado (RS), Brasil. Brasília (DF): ABEn; 2005. Disponível em: URL: http:// bstorm.com.br/enfermagem

18. Cogo ALP, Silveira DT, Lírio AM, Severo, CL. A utilização de ambiente virtual de aprendizagem no ensino de suportes básico e avançado de vida. Rev Gaúcha Enferm 2003; 24(3): 373-9. 